\title{
Supporting Elderly People's Cognitive Rehabilitation with IPad based Serious Games
}

\author{
A. Rodríguez-Isasi \\ DeustoTech-Life Unit (e-Vida) \\ University of Deusto \\ Avda. Universidades, 24 \\ 48007, Bilbao. Spain \\ ale.rois@opendeusto.es
}

\author{
A. Méndez-Zorrilla \\ DeustoTech-Life Unit (e-Vida) \\ University of Deusto \\ Avda. Universidades, 24 \\ 48007, Bilbao. Spain \\ amaia.mendez@deusto.es
}

\author{
B. García-Zapirain \\ DeustoTech-Life Unit (e-Vida) \\ University of Deusto \\ Avda. Universidades, 24 \\ 48007, Bilbao. Spain \\ mbgarciazapi@deusto.es
}

\begin{abstract}
The system described in this document consists in the design, development and evaluation of Serious Games/activities for the cognitive rehabilitation and entertainment of elderly people. The main objective of the system is to help this group improve some of their skills, such as spatial vision, memory or attention using puzzles and bingo activities. The mental effort required for assembling the pictures acts as a stimulus to sharpen those abilities, and by playing they increase their attention skills. The set of games monitor all the steps taken by the players, showing them different activities developed for multitouch platforms. The system was tested on a group of 20 seniors. The values obtained indicated some differences between the proposed related to the time used to complete the task and the level of difficulty being the bingo less accepted (only 6 wanted to continue with the highest levels of this activity). Thus, they have less problems with spatial vision than with reading speed or attention.
\end{abstract}

\section{Categories and Subject Descriptors D.8.0, C 5.3}

\section{General Terms}

Design, Experimentation, Human Factors.

\section{Keywords}

Seniors, Cognitive Rehabilitation, Touch devices, Telemonitoring, Serious Games.

\section{INTRODUCTION}

Several studies have indicated an increase in the number of people over 65 years of age in Spain in recent years, and most specifically in Biscay, where this study has been developed. This group currently comprises approximately $20 \%$ of the population $[1,2]$. In fact, a significant increase in the average age of the population in the EU in the last two decades has been noted, reaching an old-age dependency ratio of $26.2 \%$ (approximately four working-age people per each person over 65 years of age) in

Permission to make digital or hard copies of all or part of this work for personal or classroom use is granted without fee provided that copies are not made or distributed for profit or commercial advantage and tha copies bear this notice and the full citation on the first page. To copy otherwise, to republish, to post on servers or to redistribute to lists, requires prior specific permission and/or a fee. REHAB 2014, May 20-23, Oldenburg, Germany Copyright (C) 2014 ICST 978-1-63190-011-2 DOI 10.4108/icst.pervasivehealth.2014.255327
2011 [3].

Additionally, forecasts indicate that the ageing population will continue to increase, with the number of people over 60 years of age tripling in countries across the world in the next 40 years [4]. Spain is one of the countries whose populations will have over $30 \%$ of elderly people, together with Germany, Switzerland, Italy or Japan.

Hence, methods and measures to care for older people have been developed. Within this area, new technologies have played a fundamental role for several years, thanks to the possibilities ICTs offer with the different tools from utilities that have been developed for various purposes, mainly to improve the quality of the services rendered and cost savings.

Taking into account the current economic situation and the number of people over 60 years of age (a very representative part of the population, which can benefit from eHealth applications), there is a clear need to change the structure and the current care standards. The project described in this article focuses on this field. The fact that the games can be played at the users' convenience and from the comfort of their homes makes them easy to use, increasing willingness to perform the tasks and reducing expenditure and time for medical centers.

Serious games intended for cognitive rehabilitation such as those in the application described in this article, and the devices used (IPad) are more manageable and mobile than other videogames, making them perfect for users with physical limitations [5].

\section{OBJECTIVES}

The overall objective of this project is cognitive rehabilitation of elderly persons by using games. It can be broken down as follows:

- Design and develop a puzzle game to improve users' memory and spatial vision.

- Design and develop a bingo game to improve users' attention, spatial vision and reading speed.

- Implement the games in an intuitive attractive application to entertain users.

- Implement a system with a database to send the results and display them on a webpage.

- Develop an evaluation methodology based on quality of life and satisfaction surveys. 


\section{MATERIAL AND METHODS}

This section describes the materials and methodology used when creating the system.

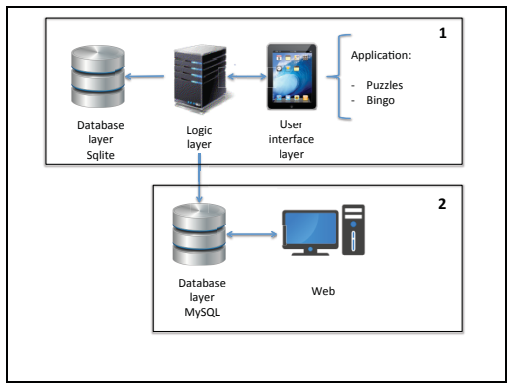

Figure 1. High-level design diagram

\subsection{System design}

\subsubsection{High level design}

The system described in this paper follows the high level design diagram shown in Figure 1.

The system architecture is based on a three layer design: a user interface layer, database layer and logics layer. The integrated development environment by Apple, Xcode, was used for the logic layer, being an application for IPad devices. The data obtained on the cognitive rehabilitation activities in the application are collected and saved on the device using Sqlite as well as on an online MySQL database. The user interface layer contains the IPad games interface (described in greater detail in the following section 3.1.2) and the web platform where the data saved can be displayed and analysed by users and specialists.

Figure 1 also shows the system divided into two main parts (numbered 1 and 2): the first comprises the device and its own database. In other words, this part is mostly for users while the second part focuses on data telemonitoring and consists of the online database and web platform services.

\subsubsection{Low level design}

This section contains a more in-depth description of the how the exercises in the application work.

Figure 2 shows how the application works.

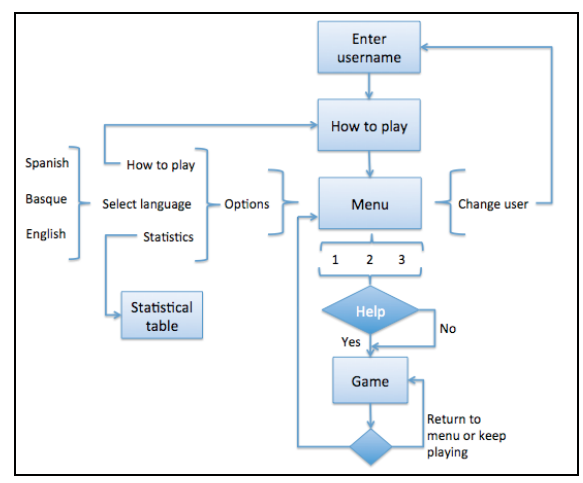

Figure 2. General low-level diagram

Firstly, a username is entered (or assigned user code). This is recorded and kept by the system during the games and the results are saved under that username (or code).

The user then selects a rehabilitation game/activity (puzzles or bingo). After reading some brief game instructions, the user goes to the main game menu. There he/she can perform different actions such as changing the username, the language, the level of difficulty, the game and start playing.

All offered activities have three levels of difficulty that can be selected from each game's main menu or the options menu. The number of pieces the image is divided into determine the level of difficulty for the puzzle games (in level 1 , the image is divided into three parts, in level 2 into six and in level 3 into nine). The higher the level in the bingo games, the more complex the words are.

\section{A) Puzzles Activities}

Puzzle activities have been chosen to work with the elderly trying to improve their memory and spatial vision.

Figure 3 shows how the puzzle game works: Firstly, the entire image is displayed for 10 seconds so that the user can try to memorise it and notice the details. The image is then divided into pieces and the user has to drag them into the correct positions on the main board. When checking, the system notifies the user if there is an error and he/she must move the pieces and try again. When the game has been correctly completed, a short explanation of the image content is displayed, and the user is given the option to continue playing (the level of difficulty increases as puzzles are completed) or exit.

As was mentioned, the user can select the desired level before beginning the game. As he/she completes puzzles, the levels become more difficult. When selecting the level, a help button can be activated which allows the user to return to the display of the original image at any time during the game.

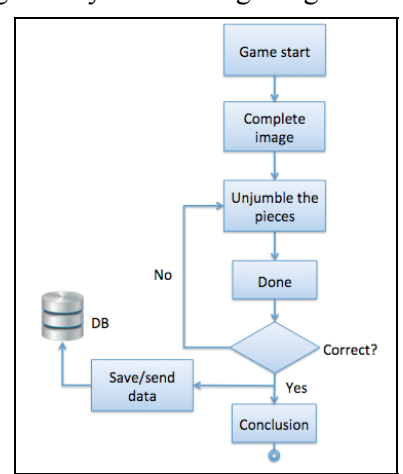

Figure 3. Puzzle game architecture

Figure 4 shows a screenshot of the puzzle game. This is a shot of level 2 with the image divided into 6 pieces. The main board and the help button (upper left) are also shown.

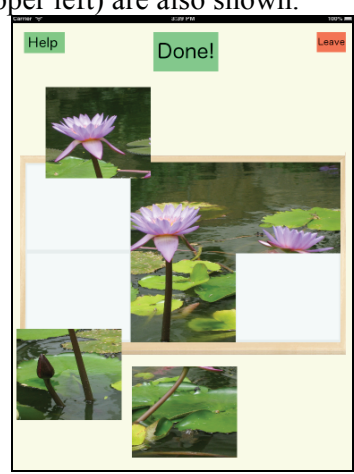

Figure 4. Screenshot of the puzzle game 
There are two puzzle game modes: the standard mode consisting of a series of predefined images with increasing levels of difficulty as the user solves the puzzles. The individual mode enables the user to make a puzzle with a photograph taken from the library on the IPad (once the image has been selected, the game mode is the same as the standard mode explained in the diagram in Figure 3, but without any information having been recorded).

\section{B) Bingo Activities}

This game is similar to conventional bingo but has words instead of numbers, as shown in the diagram in Figure 5. This exercise focuses on improving the player's attention skills since he/she has to watch the words that are scrolled across the top part of the screen and mark them on his/her card. Each word on the card appears once, together with other words that are not on the card. Like the previous game, different levels of difficulty can be selected on the options menu. Difficulty depends on how complex the words are.

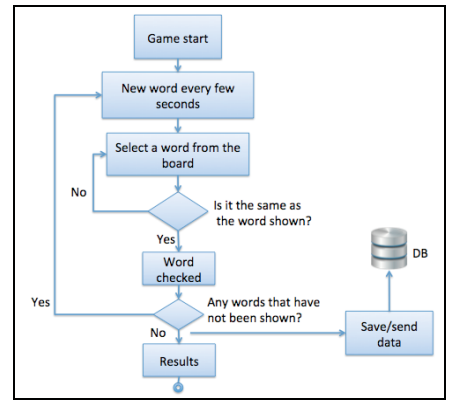

Figure 5. Bingo game architecture

Figure 6 shows a screenshot of a bingo game. The word that the player has to find on his/her card is shown on the upper part of the screen. When the player chooses the right word, it will be crossed out with an " $\mathrm{X}$ " as shown in the picture.

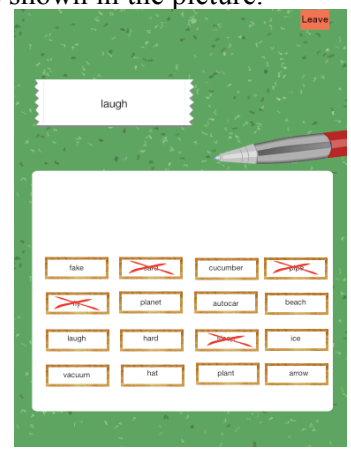

Figure 6. Screenshot of the bingo game

\subsection{Participants}

3.2.1 Ethics Statement

All the participants in this study have signed a written consent, with verbal assent was also being required in some cases, prior to starting the tests.

\subsubsection{Recruitment and eligibility}

All the participants have been recruited by the company Zuentzat in the Biscay area.
Inclusion criteria for target participants are: a) age between 65 and 90 years, b) confirmed medical diagnosis of some type of cognitive disease, c) resident in an urban area, d) integrated in social life, d) no mobility problems. Sample characteristics can be seen in Table 1 .

Table 1. Participant description

\begin{tabular}{|c|c|c|c|}
\hline & $\begin{array}{c}\text { Frequency } \\
\text { (n [\%]) }\end{array}$ & $\begin{array}{c}\text { Average } \\
\text { (SD) }\end{array}$ & $\begin{array}{c}\text { Min / } \\
\text { Max }\end{array}$ \\
\hline $\begin{array}{c}\text { Gender } \\
\text { Women } \\
\text { Men }\end{array}$ & $19[95]$ & & \\
Age & $1[5]$ & & \\
\hline Level of studies & & $73,25(9,07)$ & $56 / 90$ \\
Primary & $8[40]$ & & \\
Secondary & $5[25]$ & & \\
Medium level university & $5[25]$ & & \\
High level university & $2[10]$ & & \\
\hline
\end{tabular}

\subsection{Evaluation methods}

The following tools were used to assess the results of the study and the development of Serious Games:

- Quality of Life questionnaire. WHOQOL-Bref [6]

- Satisfaction questionnaire (designed by the authors and adapted to the project for use with the elderly)

- The users' scores throughout the study.

\section{RESULTS}

In this section, results related to QoL, satisfaction and the scores of the activities are described.

\subsection{WHOQOL- Bref questionnaire results}

WHOQOL-BREF questionnaire evaluates the quality of life and health perception in different aspects of life: somatic. Psychological, social and environmental, in relation to a particular disease. 17 people of our group have answered to this questionnaire and the provided results can be seen in table 2 .

Table 2. Quality of life evaluation by WHOQOL-BREF

\begin{tabular}{|l|l|l|}
\hline Aspects & Average (SD) & Min / Max \\
\hline Physical & $70,27(14,57)$ & $42,86 / 92,86$ \\
\hline Psychological & $64,71(13,10)$ & $45,83 / 87,50$ \\
\hline Social interactions & $62,76(26,41)$ & $0 / 100$ \\
\hline Environment & $70,04(10,60)$ & $53,13 / 87,50$ \\
\hline $\begin{array}{l}\text { General questions (range } \\
\text { 1-5) }\end{array}$ & Average (ST) & Min / Max \\
\hline $\begin{array}{l}\text { Satisfaction from general } \\
\text { quality of life }\end{array}$ & $3,94(0,56)$ & $3 / 5$ \\
\hline Satisfaction from health & $3,59(0,71)$ & $2 / 5$ \\
\hline
\end{tabular}

\subsection{Cognitive Rehabilitation activities Results}

The results are going to be described per activity: puzzles and bingo.

\subsubsection{Puzzle activities Results}

During the first level $88,9 \%$ of the participants have used the "help botton" to complete the proposed puzzle. 
In Figure 6, we can see the time they needed to complete the first activity in axis $\mathrm{X}$, and each participant in axis $\mathrm{Y}$. The average time is 42,79 seconds.

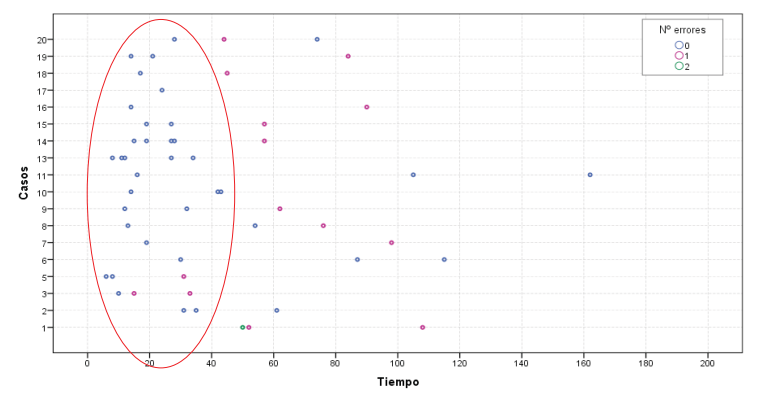

Figure 6. Puzzle Activities. Level 1 Results

In Figure 7, we can see the results per participant in level 3. All of them needed help to finish the puzzle, and it took them 148,18 seconds (average) to complete each proposed activity.

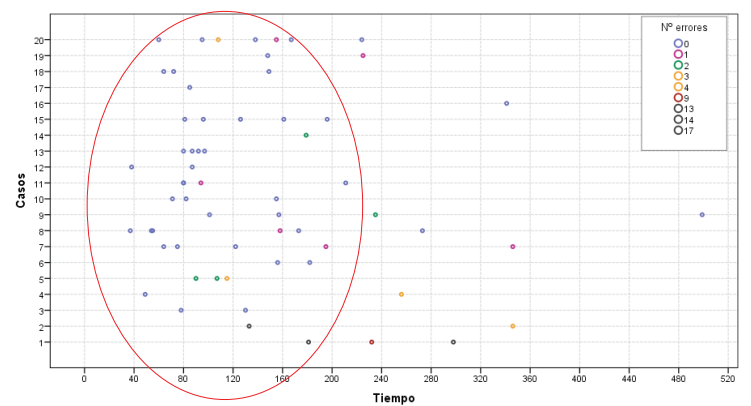

Figure 7. Puzzle Activities. Level 3 Results

4.2.2 Bingo activities Results

In this case the results are the same line, but they feel that Bingo is much more difficult. Only 6 people have played at levels 2 and 3 due to the occurrence rate of the words.

\subsection{Satisfaction Survey Results}

The authors design their own satisfaction survey to extract information about: graphical interface, what things they change, if they need support to use the iPad device...

Table 3. Satisfaction survey general result (being 8 the highest score)

\begin{tabular}{|l|l|l|}
\hline Question & Media (DT) & Min / Max \\
\hline Global satisfaction & $6,72(0,60)$ & $5,75 / 7,50$ \\
\hline
\end{tabular}

All the participants like to play with the iPad (see an example in figure 8). They consider attractive the photos and the interface provided and easy to use.

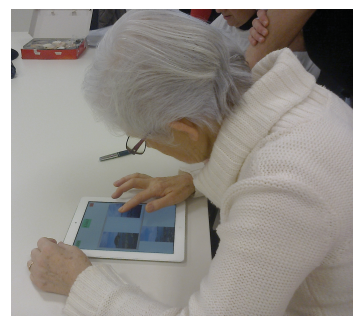

Figure 8. Users testing the puzzle activities

\section{CONCLUSIONS}

It has developed a series of activities to support cognitive rehabilitation for older people. In general, participants felt that their quality of life is good and the application has been widely accepted.

Finally, the relevance of this project is based on the benefits these activities using new technologies bring to the increasing group of elderly people and to the modern health and care systems.

\section{ACKNOWLEDGMENTS}

Our thanks to Bilbomatica and Zuentzat Company for recruiting users for the study and Deustotech-Life researchers Kattalin Camara and Asier López for their support.

\section{REFERENCES}

[1] Deia. "El 20\% de la población vasca tiene más de 65 años". April 2013 http://www.deia.com/2013/04/30/sociedad/euskadi/casi-el20-de-la-poblacion-vasca-tiene-mas-de-65-anos.

[2] M. Sancho, E. del Barrio, J. Yanguas, Fundación INGEMA. "Estudio sobre la realidad de las personas mayores de 60 años en el País Vasco". August 2010. http://www.gizartelan.ejgv.euskadi.net/r45contss/es/contenidos/informacion/estadisticas ss/es estadist/ adjuntos/ECVPM-Euskadi INF.RESULTADOSv4.pdf.

[3] European Commission, Eurostat: Population structure and ageing. October 2012 http://epp.eurostat.ec.europa.eu/statistics explained/index.ph p/Population structure and ageing

[4] T. Rutherford. "Population ageing: statistics". February 2012. Parliament. http://www.parliament.uk/briefingpapers/sn03228

[5] J. S. Wallace Yuen, C. Lutteroth, B. Wünsche. "Mobile Games for Elderly Healthcare". July 2010. Department of Computer Science, University of Auckland. http://citeseerx.ist.psu.edu/viewdoc/download?doi=10.1.1.18 6.2230\&rep=rep $1 \&$ type $=$ pdf

[6] World Health Organization: WHO Quality of Life-BREF (WHOQOL-BREF).

http://www.who.int/substance abuse/research tools/whoqolb $\underline{\text { ref/en/ }}$ 